\title{
Analysis of stratified teaching in colleges' piano courses
}

\author{
Xiaoxia Zhang \\ Hebei North University, Zhangjiakou, 075000, China
}

Key words: Colleges; Piano; Courses; Stratified teaching

\begin{abstract}
Considering the situation that propagation speed of piano is accelerated in China and batches of piano educators work sturdily, piano education of China has had brand-new leaps. Stratified teaching is a teaching concept that teaching is carried out according to different situations of learners, such as age, ability and talent. In colleges' piano teaching, it is necessary to implement more flexible stratified teaching according to the level at which learners stay in order to realize purposes of piano education. This thesis analyzes current situations of Chinese piano education and imagination about stratified teaching and puts forward specific content of stratified teaching in colleges’ piano courses.
\end{abstract}

\section{Introduction}

Since piano teaching entered colleges' classroom, it has shown strong vitality. Meanwhile, the number of its learners increases constantly and their music accomplishment is improved well. However, colleges' piano teaching in traditional sense still follows the one-to-one teaching mode, which proposes high requirements for teachers. However, colleges lack piano teachers to a large extent. Once one-to-one teaching is carried out, teachers will have many students to teach. As a result, teaching effect will be reduced sharply. Nevertheless, large-scale class teaching will make students lack improvement in practical skills and result in the situation that some students have grandiose aims but puny abilities and suffer poor practical ability. Considering the foregoing factors, it is imperative to reform existing piano teaching methods of colleges deeply and the key point of reform lies in considering difference in learners' individuation more sufficiently. For this, stratified teaching method emerges at the right moment.

\section{Current situations of Chinese piano education and imagination about stratified teaching}

As an important component in music education, piano education has obtained rapid development since it was spread from foreign counties to China. Especially, as Chinese people's living standard improves constantly, people have more pursuit for their culture. This is the reason why piano education is increasingly flourishing. However, rapid development of piano education also causes many problems. Firstly, it brings problems related to structure of the education sector. Nowadays, all of the top 9 music colleges of China establish piano major. Meanwhile, several hundred comprehensive colleges in China also establish piano major and recruit more than 10,000 students majoring in music. Several million students learn piano, tens of thousands of people are engaged in piano and there are several hundred high-level piano playing experts. This is the current situation of piano education in China. Secondly, solve the conflict between learners' original learning intention and content of traditional piano teaching. Currently, most of people aim at having high aesthetic accomplishment and appreciation capacity by learning piano. However, boring and simple teaching methods appear to have no fun, which reduces piano learners' initiative largely. If traditional piano education aims at cultivating professional talent for piano career or popularization of piano music, piano education of China has gradually developed into fashion-orientation education in the aspect of humanistic quality in recent years. This enables musical language art to be extended and developed and develops piano education into a basic project for cultivation of high-quality talent cultivation, which decides that piano teaching mode should not let all people use the same set of teaching materials or the same teaching method. For this, the author tries to analyze how piano education carries out stratified teaching in the aspect of teaching. What is stratified teaching? Here, 
'layer' mainly evolves from a pyramid structure. Stratified teaching means teachers divide students into different elves according to various factors, such as learners' music talent, demands and developmental trends, and adjust teaching materials, teaching methods and teaching goals in accordance with different layer demands. Different piano teaching types may not only intersect with one another and be changed into one another but also affect and act on one another. In stratified teaching, piano teachers of colleges should adjust teaching according to practical situations of learns when they learn piano but must not draw a final conclusion from this. The reason for this is that factors related to people have variability.

\section{Specific content of stratified teaching in colleges' piano courses}

\section{(I) Stratified teaching according to students}

For stratified teaching according to students, assessment need be implemented first and then class grouping should be performed. Before class grouping, colleges' piano teaching has accesses college students and group tem according to their different playing degrees. With respect to grouping, it is essential to investigate all students comprehensively and profoundly. Comprehensiveness mainly involves students' skills, expressive force and musicality are investigated based on the performance that students give to a certain piece of music. In doing so, current degree of students can be determined. Via college students' performance about musical scale and chord, we may deeply investigate their basic skills and observe whether they accord with degree of music or not. Profoundness mainly means it is necessary to ask colleges students about their piano learning time and learning situations more detailedly in addition to the foregoing investigated elements. Then, group college students according to results of investigation and such students' practical ability. In accordance with groups, teaching plans and tasks specified by teaching outline, master teaching schedule in order to finish teaching work well. The number of members in each group should be moderate. If the number is too large, it will be impossible to ensure teaching effect. If the number is too small, it will be difficult to reflect teaching advantages of collective teaching. In the process of piano teaching, teachers may use the principle 'excellent students go to a higher level but poor students go to a lower level' to drive students work harder and harder. After students have learned for a period, teachers should make re-adjustment according to students' job schedule and degree, which means a platform where college students can compete better is provided to improve their learning consciousness and enthusiasm.

\section{(II) Stratified teaching according to teaching methods}

Once college piano teachers learn more about concepts about diversity of teaching methods, their relation with students will be more comprehensively, teachers' basic knowledge will be more extensive and their teaching methods will be more flexible and more effective. Thus, integrating several selected methods is the most optimal method. In the process of piano course teaching, it is essential to give key coaching to college students whose learning schedule is slow, solve various kinds of difficulty in learning process and provide corresponding additional assignment for learners whose progress is rapid in order to create new and higher-level zones of proximal development for college students constantly. Piano teachers of colleges should learn the situation that college students master basic skills by links, such as individual inspection and individual coaching and solve all specific problems practically according to personalized features. In doing so, they can not only adapt to difference in college students' individualization but also remit the conflict between students whose level stay at two ends (some of them do not have enough to learn while some others cannot accept all knowledge provided by teachers) so as to implement the principle 'teaching students in accordance with their aptitude' comprehensively. Piano teachers of colleges should change the original 'baby-sitter' teaching method practically, work hard to improve learning ability of college students at each level and guide college students at different levels to digest the knowledge and skills they have learned, discover problems by themselves and solve problems practically. 


\section{(III) Stratified teaching according to teaching content}

Piano course teaching of colleges must master completeness of teaching system and structure practically and attach much importance to instruction of basic theory, content and methods rather than have too much subjectivity and impromptu nature. For piano teaching of colleges, this begins to appear to be quite important. Only teachers with high level can be qualified really. Foundation is the most solid and the most perfect component required by a house. What it needs should be strength rather than beautiful decoration or embellishment and all of its things must be sturdy and stable and can undertake pressure and time tests in the process of use. Piano teachers should impart piano playing theories and skills in a planned and gradual way according to piano course teaching plans that have been set in advance, and use screw-type method to enhance basic concepts and essentials to different degrees practically. In order to ensure teaching reform can be carried out effectively, teachers should combine basic teaching goals with specific teaching plans of each term closely and integrate standards with different conditions of college students so as to formulate teaching schedule plans more flexibly. Teaching content may be divided into four different levels according to four terms. The first level mainly involves basic piano knowledge, whose subjects are basic skill training of students. Musical works mainly lay particular emphasis on Bach polyphony and music of Western Europe classical music school and contain some Chinese music. Teaching methods run through piano teaching. The second level focuses on developing basic skill training, including Chinese and foreign music; and training about song accompaniment is added at the later semester. Piano playing should not pay attention to technique training but also attach important to analyzing piano music works deeply and cultivating musical expressive force. The third level still involves basic skill training but music works of Romanticism and modern and times are added to music. In specific piano playing, it is essential to pay attention to letting college students look for materials and listen to recording by themselves in order to strengthen their comprehension and make them learn how to deal with music independently. In colleges' piano teaching, song accompaniment should be added, which mainly includes content in the aspect of impromptu accompaniment. The fourth level mainly directs at basic skill training and skill training by asking each student to play different music in teaching and contact with piano music works of China and foreign countries widely. Pay attention to song accompaniment, including improvement in capacity of impromptu accompaniment. Cultivate piano teachers' comprehensive teaching ability by carrying out piano teaching so as to adapt to personalized development of college students.

\section{(IV) Stratified teaching according to teaching forms}

Firstly, carry out collective teaching. Piano teaching is not individualized instruction. Currently, some teachers have difficulty in walking out of restriction of individualized instruction when give lessons so that they still center on inspecting assignment one by one and correcting problems separately. Such a method cannot give full play to advantages and features of collective teaching but appears to be arduous but fruitless. Thus, it is essential to insist on giving collective teaching to college students according to their levels. This does not represent that college students are asked to play in unison but implement several methods like unison, alternative playing, solo and group competition according to alternation in order to improve group effect of collective teaching and animate atmosphere of piano teaching practically, arouse all learners' learning enthusiasm effectively and make all of them have something to do at any moment. To overcome playing mistakes of some learners efficiently, teaches may extract corresponding typical examples to carry out individualized guidance simultaneously. However, the most ideal way is to treat it as an open class to give lessons and enable other college students to attract corresponding lessons from this and take related warnings. Secondly, increase ratio of ensemble and tutti. According to different levels of college students, select or compile musical score of ensemble and tutti, respectively. Ask college students with a lower level to play easier parts and let students with a higher level to play more difficult parts to make all of them be qualified happily. Via unison, teachers can make college students play the music that the learned in the previous class jointly. After unison, teachers should focus on proposing advantages and disadvantages in skill exercises and specifying requirements of playing further. By group matches, teaches may divided students into two groups, i.e., one group 
play the piano, while the other group carries out observation, analyses and discussion etc., hoping to find existing disadvantages. Obviously, playing effect of ensemble and tutti is better than solo and unison and can arouse college students' emotion and enthusiasm to a larger extent. Teachers may make college students take part in this in the form of small concerts, each person is both a player and audience and each students play a piece of music, respectively, and keep on going. In the playing process, piano teachers do not give coaching or stop students to keep good concert atmosphere and strengthen effect of college students' practice and exercise.

\section{(V) Stratified teaching according to evaluation standards}

It is essential to form a whole set of complete stratified evaluation system that is appropriate for piano teaching. The evaluation system refers to quantitative and qualitative value judgment on changes in college students' academic performance according to teaching goals. College students' academic evaluation mainly contains the following connotations: firstly, systematic observation activities whose main object is teaching; secondly, a kind of teaching activities using teaching goals as bases; thirdly, a cognition activity whose central content is value judgment; and fourthly, a scientific activity using mental measurement as its basis. Stratified evaluation should be featured by openness, development and comprehensiveness. For this, we ought to weaken selecting function constantly, consolidate stimulating function, reduce evaluation on results and improve assessment on process and development. College students' learning beliefs, attendance rate and progress situation should be included in assessment. Thus, we should change evaluation on college students' performance by playing difficulty and quality only, comprehensively evaluate college students' skills and quality and expand unitary investigation on learners' playing ability to the one on capacity of impromptu accompaniment. Consequently, corresponding units should formulate perfect and detailed assessment rules, have enforceability and ask teachers and students to follow such rules clearly and strictly.

\section{Conclusion}

To sum up, researches on piano teaching methods are of more practical significance considering continuous improvement in Chinese colleges' piano courses. According to facts, it has been proved that stratified teaching in colleges' piano courses plays an important role in enhancing college students' learning enthusiasm and improving traditional teaching methods. However, stratified teaching in colleges' piano courses cannot be finished immediately. Indeed, al piano educators need deepen their cognition, summarize lessons and thus improve effectiveness of colleges' piano teaching as much as possible.

\section{References}

[1] Gao Rui. Thinking on piano teaching reform of local normal colleges [J]. Journal of Qujing Normal University, 2009(1).

[2] Yang Xiangyong. Effective ways to optimize piano teaching modes of normal colleges [J]. Journal of Anyang Teachers College, 2009(8).

[3] Che Zidan. Trial of stratified piano teaching of professional high schools [J]. Heilongjiang Scientific and Technological Information, 2010(5).

[4] Wu Weiwei. Exploration on effectiveness of stratified piano teaching of preschool education major [J]. Popular Literature, 2011(22).

[5] Zhang Qian. Exploration on practice of stratified piano teaching of preschool education major [J]. Journal of Hubei University of Science and Technology, 2013(8). 